\title{
Layer-Specific Interference with Cholinergic Signaling in the Prefrontal Cortex by Smoking Concentrations of Nicotine
}

\author{
Rogier B. Poorthuis, Bernard Bloem, Matthijs B. Verhoog, and Huibert D. Mansvelder \\ Department of Integrative Neurophysiology, Center for Neurogenomics and Cognitive Research, Neuroscience Campus Amsterdam, VU University, \\ Amsterdam, De Boelelaan 1085, 1081HV, The Netherlands
}

Adolescence is a period in which the developing prefrontal cortex (PFC) is sensitive to maladaptive changes when exposed to nicotine. Nicotine affects PFC function and repeated exposure to nicotine during adolescence impairs attention performance and impulse control during adulthood. Nicotine concentrations experienced by smokers are known to desensitize nicotinic acetylcholine receptors (nAChRs), but the impact thereof on PFC circuits is poorly understood. Here, we investigated how smoking concentrations of nicotine (100-300 nM) interfere with cholinergic signaling in the mouse PFC. nAChR desensitization depends on subunit composition. Since nAChR subunits are differentially expressed across layers of the PFC neuronal network, we hypothesized that cholinergic signaling through nAChRs across layers would suffer differentially from exposure to nicotine. Throughout the PFC, nicotine strongly desensitized responses to ACh in neurons expressing $\beta 2^{\star}$ nAChRs, whereas ACh responses mediated by $\alpha 7 \mathrm{nAChRs} \mathrm{were} \mathrm{not} \mathrm{hampered.} \mathrm{The} \mathrm{amount} \mathrm{of} \mathrm{desensitization}$ of $\beta 2^{\star} \mathrm{nAChR}$ currents depended on neuron type and cortical layer. $\beta 2^{\star}$-mediated responses of interneurons in LII-III and LVI completely desensitized, while cholinergic responses in LV interneurons and LVI pyramidal cells showed less desensitization. This discrepancy depended on $\alpha 5$ subunit expression. Two-photon imaging of neuronal population activity showed that prolonged exposure to nicotine limited cholinergic signaling through $\beta 2^{\star} \mathrm{nAChRs} \mathrm{to} \mathrm{deep} \mathrm{PFC} \mathrm{layers} \mathrm{where} \alpha 5$ subunits were expressed. Together, our results demonstrate a layer-dependent decrease in cholinergic activation of the PFC through nAChRs by nicotine. These mechanisms may be one of the first steps leading up to the pathophysiological changes associated with nicotine exposure during adolescence.

\section{Introduction}

Despite negative health consequences, tobacco smoking remains a persistent drug addiction worldwide (World Health Organization, 2012). First experiences with cigarette smoking often take place during adolescence (Escobedo et al., 1993; Currie et al., 2008). The prefrontal cortex (PFC), which is involved in higher order processes such as attention, impulse control, and working memory (Groenewegen and Uylings, 2000; Miller, 2000), continues to develop during this period (Gogtay et al., 2004). As a consequence, exposure to nicotine during adolescence compromises normal PFC development (Counotte et al., 2011b; Goriounova and Mansvelder, 2012a). Repeated exposure to nicotine transiently increases nicotinic acetylcholine receptor subunit (nAChR) expression and GABAergic synaptic transmission in the PFC (Counotte et al., 2012). Secondary to this, a decrease of mGluR protein persists into adulthood and causes altered synap-

Received Oct. 25, 2012; revised Jan. 7, 2013; accepted Jan. 26, 2013.

Author contributions: R.P., B.B., and H.D.M. designed research; R.P., B.B., and M.B.V. performed research; R.P. and B.B. analyzed data; R.P. and H.D.M. wrote the paper.

Funding was received from the Netherlands Organization for Scientific Research (NW0; 917.76 .360 and 912.06.148), ERC StG "BrainSignals," the Dutch Fund for Economic Structure Reinforcement (FES, 0908 “NeuroBasic PharmaPhenomics project"), EU 7th Framework Programme (HEALTH-F2-2009-242167 "SynSys"), and VU University Amsterdam. We thank Hans Lodder, Brendan Lodder, and Dr. Christiaan de Kock for technical assistance, and Dr. Uwe Maskos for providing the nicotinic receptor knock-out mice.

The authors declare no competing financial interests.

Correspondence should be addressed to Huibert D. Mansvelder, De Boelelaan 1085, 1081HV Amsterdam, The Netherlands. E-mail: h.d.mansvelder@vu.nl.

DOI:10.1523/JNEUROSCI.5012-12.2013

Copyright $\odot 2013$ the authors $\quad 0270-6474 / 13 / 334843-11 \$ 15.00 / 0$ tic learning rules and attention behavior (Counotte et al., 2011a; Goriounova and Mansvelder, 2012b). Despite these insights into long-term changes of PFC function after nicotine exposure, it is still unclear what the initial mechanisms are by which nicotine alters cortical processing at the neuronal network level.

Rapid, phasic cholinergic signaling within the PFC is crucial for attention behavior (Parikh et al., 2007; Sarter et al., 2009) and disturbances in cholinergic signaling impair attention (Turchi and Sarter, 1997; Newman and McGaughy, 2008). nAChRs are fast ionotropic receptors and their activation kinetics suggests that they are efficiently activated by rapid increases in acetylcholine. Attention performance depends on functional nAChRs in the medial PFC (Guillem et al., 2011). Nicotinic receptors activate the PFC in a layer-specific manner (Poorthuis et al., 2013). In superficial layers only interneurons are activated, whereas in deeper layers pyramidal neurons and interneurons are modulated by nAChRs. Short exposure to nicotine alters synaptic transmission and rules for plasticity induction (Couey et al., 2007). However, during smoking, blood levels of nicotine in smokers remain elevated and reach peak levels of 300-600 nM (Matta et al., 2007). These concentrations desensitize neuronal nAChRs (Mansvelder et al., 2002; Wooltorton et al., 2003; Grady et al., 2012). It is not known whether desensitization plays an important role in the PFC. The presence of $\alpha 5$ subunits protects $\beta 2$-containing receptors in layer VI pyramidal neurons from desensitization (Bailey et al., 2010). In the PFC, $\alpha 5 \mathrm{nAChR}$ subunits are highly expressed (Counotte et al., 2012), but $\alpha 5$ subunit expression has been reported to be much lower in superficial corti- 
cal layers (Wada et al., 1990; Winzer-Serhan and Leslie, 2005). It is unknown how nicotine affects cholinergic transmission in these layers and whether $\alpha 7 \mathrm{nAChR}$ activation is affected by nicotine.

We tested the hypothesis that nicotine interferes with cholinergic activation of the PFC network through nAChRs and that this effect is more prominent in superficial layers. Using electrophysiological recordings and two-photon network imaging, we find that desensitization in response to nicotine is cell type and layer specific and that this can be explained by the presence of the nAChR $\alpha 5$ subunit. As a consequence, in the presence of nicotine, cholinergic signaling through $\beta 2^{\star} \mathrm{nAChRs}$ is restricted to layer VI.

\section{Materials and Methods}

Prefrontal cortical slice preparation. Prefrontal coronal cortical slices (300 $\mu \mathrm{M})$ were prepared from P14-P21 and P34-P43 C57BL/6 mice or $\alpha 5$ wild-type and $\alpha 5$-null littermates P34-P43 of either sex, in accordance with institutional and Dutch license procedures. Following rapid decapitation, the brain was removed from the skull in ice-cold artificial CSF containing $125 \mathrm{~mm} \mathrm{NaCl}, 3 \mathrm{~mm} \mathrm{KCl}, 1.25 \mathrm{~mm} \mathrm{NaH}_{2} \mathrm{PO}_{4}, 3 \mathrm{~mm} \mathrm{MgSO}_{4} 1$ $\mathrm{mm} \mathrm{CaCl} 2,26 \mathrm{~mm} \mathrm{NaHCO} 3$, and $10 \mathrm{~mm}$ glucose ( $2300 \mathrm{mOsm})$. After removal of the cerebellum the brain was glued on this plane to create a coronal orientation for cutting slices. Slices were then transferred into holding chambers containing aCSF $125 \mathrm{~mm} \mathrm{NaCl}, 3 \mathrm{~mm} \mathrm{KCl}, 1.25 \mathrm{~mm}$ $\mathrm{NaH}_{2} \mathrm{PO}_{4}, 1 \mathrm{~mm} \mathrm{MgSO}{ }_{4} 2 \mathrm{~mm} \mathrm{CaCl}$, $26 \mathrm{~mm} \mathrm{NaHCO} 3$, and $10 \mathrm{~mm}$ glucose $(\sim 300 \mathrm{mOsm})$ and bubbled with carbogen gas $\left(95 \% \mathrm{O}_{2} / 5 \%\right.$ $\mathrm{CO}_{2}$ ) to recover for at least an hour.

Electrophysiology. Slices were transferred to the recording chamber and perfused with standard aCSF $(2-3 \mathrm{ml} / \mathrm{min})$. All experiments were performed at $31-34^{\circ} \mathrm{C}$. Cells were visualized using differential interference contrast microscopy. Recordings were made using Multiclamp 700B amplifiers (Molecular Devices), sampled at a frequency of $20 \mathrm{kHz}$, digitized by the pClamp software (Axon), and later analyzed off-line. Patch pipettes (3-5 MOhms) were pulled from standard-wall borosilicate capillaries and were filled with intracellular solution: $140 \mathrm{~mm} \mathrm{~K}$-gluconate, 1 $\mathrm{mm} \mathrm{KCl}, 10 \mathrm{~mm}$ HEPES, 4 mм K-phosphocreatine, 4 mм ATP-Mg, and $0.4 \mathrm{~mm}$ GTP (pH 7.2-7.3, pH adjusted to 7.3 with KOH; 290-300 mOsm) and biocytin $(4 \mathrm{mg} / \mathrm{ml}$; used for EPSC and puff application experiments, reversal potential chloride $\sim-127 \mathrm{mV}$, hence IPSCs in this case are detected as outward currents). Action potential profiles of cells were made using hyperpolarizing and depolarizing current steps. For IPSC experiments a modified intracellular solution was used with a high chloride concentration ( $70 \mathrm{~mm} \mathrm{~K}$-gluconate and $70 \mathrm{~mm} \mathrm{KCl}$ ) to augment GABAergic currents (reversal potential for chloride is $\sim-16 \mathrm{mV}$, hence GABA currents are detected as inward currents). All IPSC experiments were done in the presence of DNQX $(10 \mu \mathrm{M})$. All experiments recording IPSCs or EPSCs were done in the presence of atropine (200 nM) to prevent muscarinic receptor stimulation. For network experiments, acetylcholine (1 mM) was bath applied. Nicotine (Sigma, 300 or $3000 \mathrm{~nm}$ ) was bath applied in all experiments.

Nicotinic receptor currents on interneurons and pyramidal neurons were tested by pressure ejection of acetylcholine (Sigma, $1 \mathrm{~mm}$ ) for 100 ms using a Picospritzer III (General Valve Corporation) from a glass electrode with a tip opening of $\sim 1 \mu \mathrm{m}$. The puffer pipette was located $\sim 20 \mu \mathrm{m}$ from the soma and placed in perpendicular direction with respect to the pial surface. The presence of atropine (200 nM) prevented stimulation of muscarinic receptors, and during all experiments DNQX $(10 \mu \mathrm{M})$ and bicuculline $(1 \mu \mathrm{M})$ were used to block synaptic transmission. Nicotine (Sigma, 100 and $300 \mathrm{~nm}$ ) was bath applied in all experiments.

Analysis and statistics for electrophysiological experiments. Frequency of EPSCs or IPSCs was analyzed using MiniAnalysis (Synaptosoft). Local pressure application experiments were analyzed using custom made software for Matlab (MathWorks). The effect of nicotine on cholinergic signaling was determined by calculating the charge of ACh-induced currents before, during, and after exposure to nicotine. In case cells showed a mixed $\alpha 7 / \beta 2$-mediated nAChR current, the charge of the $\beta 2$ current was calculated after the $\alpha 7$ current ended ( $\sim 300 \mathrm{~ms})$. The different receptor currents were well distinguishable by the different rise times of the two components and the full $\alpha 7$ component remained after desensitization. In addition, the $\beta 2$ currents are $>10$ times longer than $\alpha 7$ currents ( $\sim 3-10 \mathrm{~s}$ ), hence taken out the $\alpha 7$ had little influence on determining the charge of the $\beta 2$ receptor. In Figure 1, $A 3$ and B3, only the charge of the $\beta 2$ component was plotted, while the $\alpha 7$ component was not plotted. To test for frequency differences in PSCs we used a Student's $t$ test. To test for effects of pharmacology or genotype effects on nAChR charge induced by puff application of Ach, a Student's $t$ test was used. Statistical tests for stable baseline currents were done on the raw data. Statistical tests for effects of desensitization were done on normalized data and by comparing the last data point before nicotine application with the first data point after 10 min of nicotine. In all desensitization experiments, analysis was done on the charge of the nAChR currents. Significant results were obtained with $p<0.05$. $p$ values between 0.05 and 0.01 are shown as $<0.05$. $p$ values between 0.01 and 0.001 are shown as $p<0.01$ and $p$ values lower than 0.001 are shown as $p<0.001$.

Two-photon calcium imaging: loading. Slices were made as described before, but in an alternative slicing solution $(27 \mathrm{~mm} \mathrm{NaHCO} 3,1.5 \mathrm{~mm}$ $\mathrm{NaH}_{2} \mathrm{PO}_{4}, 222 \mathrm{~mm}$ sucrose, $2.6 \mathrm{~mm} \mathrm{KCl}, 0.5 \mathrm{~mm} \mathrm{CaCl} 2,3 \mathrm{~mm} \mathrm{MgSO}$. Hereafter, slices were incubated in regular aCSF at $35^{\circ} \mathrm{C}$ for $20 \mathrm{~min}$ and in room temperature for another $40 \mathrm{~min}$. For bulk loading, a modified protocol based on the study by Trevelyan et al. (2006) was used. Briefly, slices were first preincubated at $37^{\circ} \mathrm{C}$ for $5 \mathrm{~min}$ in $3 \mathrm{ml}$ of aCSF containing $8 \mu \mathrm{l}$ of Cremophor EL solution (0.5\% Cremophor EL in DMSO). After this, $1 \mu \mathrm{l}$ of Fura-2AM solution ( $25 \mu \mathrm{g}$ of Fura-2AM in $4.5 \mu \mathrm{l}$ of DMSO and $0.5 \mu \mathrm{l}$ of pluronic acid) was pipetted on top of each slice. Then, the slices were left for incubation for 35-40 min after which they were put back in the slice chamber with aCSF at room temperature for at least 45 min. Imaging experiments were performed in aCSF (perfusion speed 2.5 $\mathrm{ml} / \mathrm{min}$ ), continuously bubbled with $95 \% \mathrm{O}_{2} / 5 \% \mathrm{CO}_{2}$, at $32^{\circ} \mathrm{C}$. Imaging was performed using a multibeam two-photon laser-scanning microscope system (Trimscope, Lavision BioTec) coupled to a Ti:Sapphire laser (Chameleon, Coherent, excitation at $820 \mathrm{~nm}$ ) and a CCD camera (C9100 Hamamatsu). The objective used had a $20 \times$ magnification and a 0.95 numerical aperture. The imaged plane was always in the same orientation with respect to the pia and the distance between them was determined for later analysis. The imaged area was $400 \times 400 \mu \mathrm{m}$ (pixel size of $0.8 \mu \mathrm{m}$, binning $2 \times 2$ ) and the imaging frequency was $9 \mathrm{~Hz}$.

Experimental protocol. Baseline activity was imaged during a $4 \mathrm{~min}$ period. After this, nicotine (300 nM) was applied for $10 \mathrm{~min}$. During the first $4 \mathrm{~min}$ of nicotine perfusion, the activity in the slice was imaged. Then, ACh (1 mM) and nicotine (300 nM) were applied for 2 min after which the drugs were washed out $(8 \mathrm{~min})$. During these periods imaging took place.

Analysis. Analysis was done using custom-made software for Matlab (MathWorks). This program detected cell contours and extracted the fluorescence within these contours as a function of time. After this, cell activity was determined per minute in a blind fashion. Cells were divided in three depth groups, corresponding to the measured thicknesses of the three layers in the PFC. Neurons that were between 100 and $300 \mu \mathrm{m}$, between 300 and $550 \mu \mathrm{m}$, and between 550 and $800 \mu \mathrm{m}$ were considered to be part of layer II/III, V, and VI, respectively. For determining the activity in the different drug conditions, the percentage of neurons showing at least one calcium event was calculated per slice per minute. If slices included multiple layers, then the slice was split up into two new slices containing just one layer. Effects of drugs, layer, and condition were tested using repeated-measures ANOVA, followed by Fisher's LSD post hoc tests. After this, for direct comparison of the activations in the different cell types in the different conditions, it was determined per neuron whether the activity after ACh application was higher, lower, or equal to the amount of calcium events in the minute before ACh application. $\chi^{2}$ tests were performed to test whether this statistic was different for the multiple layers, condition, and neuron types. In addition, binomial tests were used to determine the significance of the activation for every combination.

Determination of cell identity. High resolution $z$-stacks were made to optimize the possibilities for identification (voxel size: $0.4 \times 0.4 \times 0.5$ 
A1

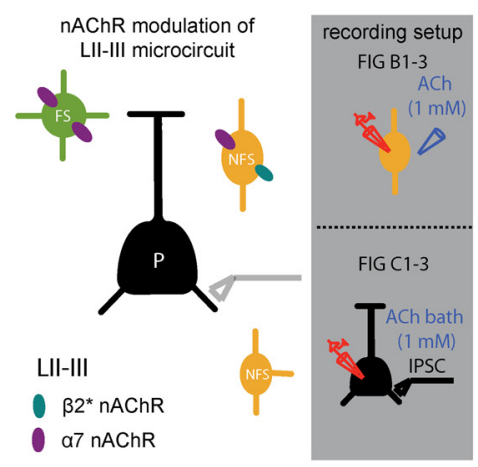

B1

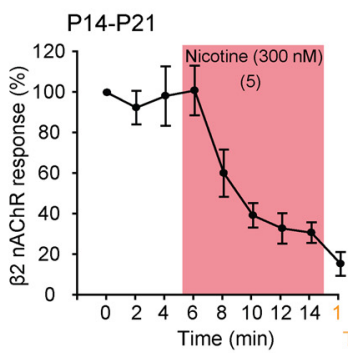

C1

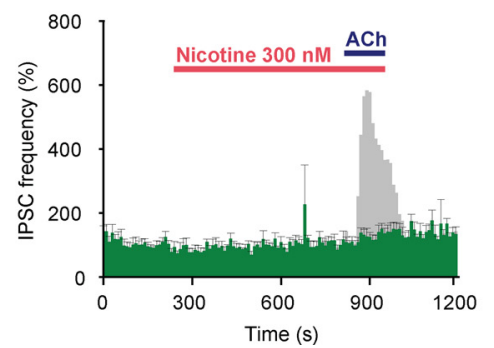

A2

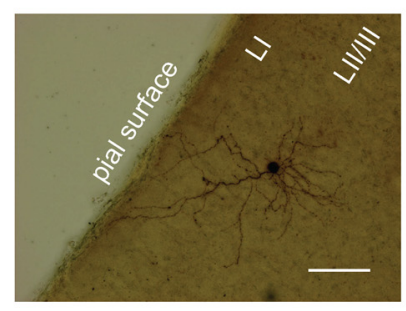

A3

A4

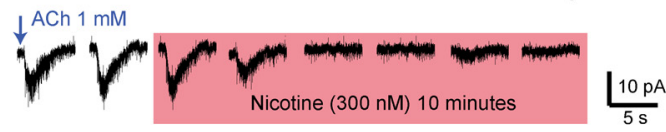

B2

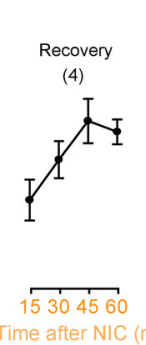

B3

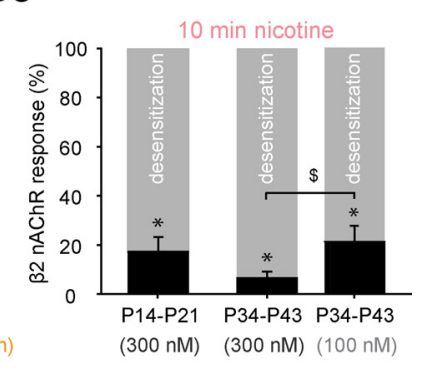

C2

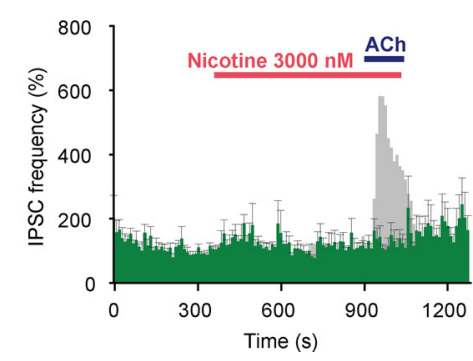

C3

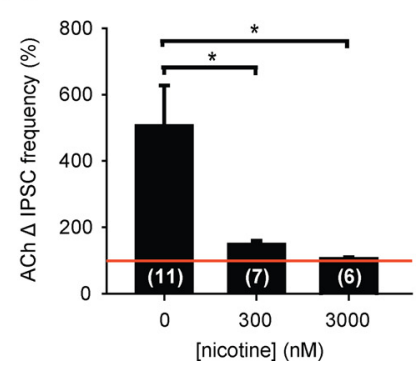

Figure 1. Desensitization of LII-III $\beta 2^{*}$-nAChR responses by smoking concentrations of nicotine. A1, Schematic showing nAChR receptor distribution in PFC LII-III microcircuitry. FS, Fast-spiking interneuron; NFS, nonfast-spiking interneuron; $\mathrm{P}$, pyramidal neuron. Gray synapse, Glutamatergic input; black synapse, inhibitory input. $\beta 2^{*}$ nAChRs and $\alpha 7$ nAChRs are indicated with turquoise and purple colored ovals. Right panel shows the recording configuration used to test for desensitizing effects of nicotine on LII-III $\beta 2^{*}$-nAChR responses. A2, Morphological staining of a LII-III NFS interneuron in the adolescent PFC. Scale bar, $100 \mu \mathrm{m} . A 3, \beta 2^{*}$ ACChRs on NFS interneurons are characterized by slow rise and decay kinetics and are blocked by DH $\beta E$ (wild type example traces). In $\beta 2$-null mice these current are absent and only short-lasting currents with a fast rise-time characteristic of $\alpha 7 \mathrm{nAChRs}$ remain [right example traces, see the study by Poorthuis et al. (2013)]. A4, Example trace showing $\beta 2^{*}$ nAChR currents in LII-III of the adolescent PFC evoked by puff application of ACh (1 mM) every 2 min. Low concentrations of nicotine ( $300 \mathrm{~nm}, 10 \mathrm{~min}$, pink shading) completely abolish $\beta 2^{*} \mathrm{nAChR}$ currents in LII-III. B1, Average surface area of current responses of juvenile LII-III NFS interneurons to local ACh (1 mM) application during bath exposure to nicotine $(300 \mathrm{~nm}, 10 \mathrm{~min})$. Current charge remains reduced when nicotine is washed out of the bath for up to $45 \mathrm{~min}$. $\boldsymbol{B 2}$, Same as in $\boldsymbol{B} 1$, but now for adolescent NFS interneurons. In gray the effect of exposure to $100 \mathrm{~nm}$ nicotine is shown. Note that the desensitization rate is slower and recovery from desensitization quicker. B3, Summary histogram quantifying the desensitizing effect of a 10 min nicotine (300 nM) application on the current charge of $\beta 2^{*}$ nAChRs in juvenile $(n=6$, Student's $t$ test, $p<0.01)$ and adolescent LII-III NFS interneurons $(n=7, p<0.01)$. The degree of desensitization was not different between the age groups ( $p=0.15$ ). The right bar shows that $100 \mathrm{~nm}$ nicotine also strongly interfered with ACh-induced $\beta 2^{*}$-mediated currents in adolescent LII-IIII NFS neurons $(n=6, p<0.01)$, but less compared with $300 \mathrm{~nm}$ nicotine $\left({ }^{\$} p=0.03\right)$. C1, Histogram showing that nicotine abolished the effect of ACh on inhibitory transmission to layer II-III pyramidal neurons. Response without nicotine is shown in gray. C2, Same experiment as in $\boldsymbol{A 1}$, but now for $3000 \mathrm{~nm}$ nicotine. C3, Summary showing the effect of nicotine on ACh induced increase of inhibitory transmission to layer II-III pyramidal neurons. Nicotine completely abolished cholinergic control over inhibitory transmission $(300 \mathrm{~nm}, n=7, p=0.03 ; 3000 \mathrm{~nm}, n=6, p=0.02)$. All statistical tests for Figures 1-6 used Student's $t$ test. * Denotes significance within test group, \$ denotes significance between test groups.

$\mu \mathrm{m})$. For the majority of neurons, proximal dendrites showed strong fluorescence. Cells were only taken into account if dendritic fluorescence was sufficient and cells could be identified as interneurons or pyramidal neurons according to the following criteria: (1) the presence of a clear apical dendrite, (2) a pyramidal-shaped cell body for pyramidal neurons; (3) a clear nonpyramidal cell body morphology; and (4) bipolar or multipolar dendrite morphologies for the interneurons. Criteria 1 and 2 classified the neuron as pyramidal. Criteria 3 and 4 classified a neuron as interneuron. If the dendrites were not visible in the $z$-stack, the neurons were not categorized. Identification of cells was done in a blind manner, i.e., the experimenter was unaware of whether neurons were activated by nicotine receptor stimulation or not, excluding the possibility of a bias. After morphological identification, data were compared with electro- physiological experiments. If neurons could not be unequivocally identified, they were excluded from statistics on cell type-specific activation.

\section{Results}

Desensitization of LII-III $\beta 2^{\star}$-nAChR current responses by smoking concentrations of nicotine

To test the hypothesis that $\mathrm{nAChR}$ currents desensitize more strongly in PFC LII-III than in LVI, we first targeted layer II-III nonfast-spiking (NFS) interneurons (Fig. 1 A2), the only cell type in this PFC layer that expresses $\beta 2$-containing $\mathrm{nAChRs}$ (Fig. 1A1) (Poorthuis et al., 2013). ACh-induced $\beta 2^{*}$ nAChRmediated currents had slow rise and decay times, were blocked by 
dihydro- $\beta$-erythriodine ( $\mathrm{DH} \beta \mathrm{E})$, and were absent in $\beta 2$-null mice (Fig. 1A3) (Poorthuis et al., 2013). nAChR currents were induced by pressure application of ACh $(1 \mathrm{~mm}, 100 \mathrm{~ms})$ at $2 \mathrm{~min}$ intervals (Fig. 1A4). These applications induced repeatable postsynaptic currents that were stable over time (Fig. $1 B 1$, the third vs the first response, $100 \%$ vs $98.4 \pm 14 \%$, Student's $t$ test, $p=0.49$ ). We then tested the effect of a 10 min nicotine application of 300 $\mathrm{nM}$, which resembles arterial blood concentration profiles during cigarette smoking (Matta et al., 2007), on these ACh-induced currents. After $10 \mathrm{~min}$ of nicotine application, responses to ACh were strongly reduced on LII-III NFS interneurons (Fig. $1 B 1,3$; $n=5,17.4 \pm 0.06 \%$ remaining response, $p<0.01)$. The reduction of ACh-induced currents remained after nicotine was washed-out from the bath for up to $45 \mathrm{~min}$ (Fig. $1 \mathrm{B1} ; n=4$; at 15 $\min , 45.2 \pm 10 \%$ remaining response, $p<0.01$; at $30 \mathrm{~min}, 64.7 \pm$ $9.0 \%$ remaining response, $p<0.05$; at $45 \mathrm{~min}, 83.4 \pm 11 \%$ remaining response, $p=0.11$; at $60 \mathrm{~min}, 78 \pm 6 \%$ remaining response, $p=0.40$ ). This suggests that $\beta 2^{\star} \mathrm{nAChRs}$ expressed by PFC LII-III NFS cells were desensitized by exposure to smoking concentrations of nicotine.

Adolescence (P34-P43) is a period in which rodents are in particular vulnerable to the effects of nicotine on PFC-dependent cognitive functioning (Counotte et al., 2011a). Nicotinic AChR subunit expression changes during development and may therefore alter the sensitivity of receptors for nicotine and desensitization. To test whether nAChR-mediated currents in the adolescent PFC similarly desensitize, we performed the same experiment in mice at this developmental period. Acetylcholine application induced stable currents (Fig. 1 B2, first vs third response, $100 \%$ vs $87.9 \pm 12.5, p=0.96)$. Nicotine application abolished AChinduced $\beta 2^{\star}$-mediated currents in adolescent LII-III NFS neurons (Fig. $1 B 2,3 ; n=7,6.7 \pm 2.5 \%$ remaining after $10 \mathrm{~min}$ of nicotine, $p<0.01)$. Similar to the ACh responses in juvenile neurons, $\beta 2^{\star}$-nAChR-mediated responses were reduced for a prolonged period of time in adolescent neurons (Fig. $1 B 2 ; n=3$, at $15 \mathrm{~min}, 10.9 \pm 2.6 \%$ remaining response, $p=0.02$; at $30 \mathrm{~min}$, $37.1 \pm 2.9 \%$ remaining response, $p=0.06$; at $45 \mathrm{~min}, 61.8 \pm$ $4.2 \%$ remaining response, $p=0.28 ; 60 \mathrm{~min} 73.7 \pm 6.0 \%$ remaining response, $p=0.99$ ), suggesting that also in adolescent PFC neurons $\beta 2^{\star}$-nAChRs strongly desensitize. Two of seven recorded cells contained a mixed $\beta 2^{*}$ - and $\alpha 7$-nAChR-mediated response. In these cells, the $\alpha 7$ component was not desensitized by nicotine (data not shown). We also tested whether a lower nicotine concentration, as observed in smokers between cigarettes in the afternoon (Matta et al., 2007), would have a desensitizing effect on nicotinic receptor currents. Application of 100 $\mathrm{nM}$ nicotine strongly reduced ACh-induced $\beta 2^{\star}$-mediated currents in adolescent LII-III NFS neurons (Fig. $1 B 2,3 ; n=5$, $21.4 \pm 6.3 \%$ remaining after $10 \mathrm{~min}$ of nicotine, $p<0.01)$, but the reduction was less compared with $300 \mathrm{~nm}$ nicotine (Fig. 1 B3, $p=0.03)$.

Activation of $\beta 2^{*} \mathrm{nAChRs}$ enhances GABAergic signaling onto pyramidal neurons in the PFC (Couey et al., 2007; Poorthuis et al., 2009, 2013). We tested whether nicotine (300 nM) interferes with cholinergic modulation of IPSCs received by LII-III pyramidal neurons by applying nicotine for $10 \mathrm{~min}$ followed by coapplication of nicotine and ACh (1 mM). In the absence of nicotine, ACh dramatically increases the frequency of IPSCs in layer II-III pyramidal neurons (Fig. $1 C 3 ; n=10,505.3 \pm 148.2 \%, p<0.01$ ). After exposure to nicotine, ACh hardly increased IPSC frequency anymore (Fig. 1C1-3; $300 \mathrm{~nm}$ nicotine, $n=7,122.7 \pm 11.3 \%, p=$ 0.06; 3000 nM nicotine, $n=6,104.8 \pm 6 \%, p=0.09$; ACh-control vs ACh-nicotine ( $300 \mathrm{~nm}), p=0.03)$. Together, these data suggest that smoking concentrations of nicotine desensitize $\beta 2^{\star} \mathrm{nAChRs}$ in LII/III. Thereby, nicotine interferes with cholinergic control through nAChRs over inhibitory circuits in superficial layers of the PFC.

\section{Smoking concentrations of nicotine do not affect cholinergic signaling through $\alpha 7 \mathrm{nAChRs}$}

In other brain areas, $\mathrm{nAChRs}$ containing $\alpha 7$ subunits suffer less from desensitization by low concentrations of nicotine than $\beta 2$ containing nAChRs (Mansvelder et al., 2002; Wooltorton et al., 2003). In the PFC, $\alpha 7$ nAChRs are expressed by LII-III and LV fast-spiking and nonfast-spiking interneurons, as well as by LV pyramidal neurons (Fig. 2 A) (Poorthuis et al., 2013). We hypothesized that in the PFC cholinergic signaling through $\alpha 7 \mathrm{nAChRs}$ is not influenced by concentrations of nicotine experienced by smokers. We targeted interneurons in LII-III positive for $\alpha 7$ nAChRs. $\alpha 7 \mathrm{nAChR}$-mediated currents had a fast rise and decay time, were blocked by methyllycaconetine (MLA), and were absent in $\alpha 7$-null mice (Fig. 2 B) (Poorthuis et al., 2013). Similar to $\beta 2^{\star}$ nAChRs, repeated ACh-induced currents mediated by $\alpha 7$ nAChRs were stable and showed a constant amount of charge (Fig. 2C, third vs first response, $100 \%$ vs $94 \pm 8 \%, p=0.3$ ). Subsequent exposure of the receptors to $300 \mathrm{~nm}$ nicotine for 10 min did not significantly alter ACh-induced currents (Fig. 2C,F; $83.0 \pm 1.4 \%$ remaining after $10 \mathrm{~min}$ of nicotine, $p=0.31)$. A similar result was obtained for layer $\mathrm{V}$ interneurons (Fig. 2D,F; $88.0 \pm 3.4 \%$ remaining after $10 \mathrm{~min}$ of nicotine, $p=0.69)$ as well as layer $\mathrm{V}$ pyramidal neurons (Fig. 2 E, F; $93.5 \pm 6.6 \%$ remaining after $10 \mathrm{~min}$ of nicotine, $p=0.25)$. Hence, these data show that nicotine concentrations seen in smokers during cigarette smoking do not hamper cholinergic stimulation of $\alpha 7 \mathrm{nAChRs}$ in the PFC.

\section{Partial interference of nicotine with $\beta 2^{\star}$ nAChR-mediated cholinergic responses in $\mathrm{LV}$}

In layer $\mathrm{V}$ of the PFC, $\beta 2^{*} \mathrm{nAChRs}$ are found on glutamatergic inputs and nonfast-spiking interneurons. Stimulating the latter increases inhibitory inputs to pyramidal neurons (Fig. 3A1) (Poorthuis et al., 2013). Nonfast spiking interneurons in juvenile mice were targeted and tested for the effect of nicotine on $\beta 2^{*}$ $\mathrm{nAChR}$-mediated cholinergic responses. A 10 min application of nicotine $\left(300 \mathrm{~nm}\right.$ ) strongly reduced $\beta 2^{*} \mathrm{nAChR}$-mediated responses (Fig. $3 A 2, A 3 ; 30.6 \pm 4.0 \%$ remaining charge, $n=9, p<$ $0.01)$. However, compared with the reduction in ACh-induced current by nicotine in LII-III NFS neurons, the reduction in NFS neurons in LV was less complete and a substantial ACh-induced current remained (Fig. 3A2,A3). Thus, $\beta 2$-containing nAChRs expressed by LV NFS neurons desensitized to a lesser extent than $\beta 2$-containing $\mathrm{nAChRs}$ expressed by LII-III NFS neurons (Fig. $3 A 3, p<0.05)$.

Spontaneous IPSCs received by LV pyramidal neurons were strongly enhanced by ACh application (Fig. 3B1,3; $n=16,351 \pm$ $41 \%, p<0.01)$. After nicotine application, ACh still increased IPSC frequency (Fig. $3 B 1,3 ; n=10,171 \pm 22 \%, p=0.03$ ), but less than in control conditions $(p<0.01)$. A high dose of nicotine (3000 nM) abolished ACh modulation through nAChRs of IPSCs (Fig. 3B2,3; $n=8,112 \pm 5 \%, p=0.08$ ). Thus, in line with the results on LV NFS neurons, nicotine only partially interfered with cholinergic modulation through $\beta 2^{\star} \mathrm{nAChRs}$ of IPSCs received by LV pyramidal neurons.

Activation of $\beta 2^{\star} \mathrm{nAChRs}$ strongly enhances glutamate release from thalamic projections to PFC LV pyramidal neurons (Lambe et al., 2003). Nicotine (300 nM) partially reduced the 
A

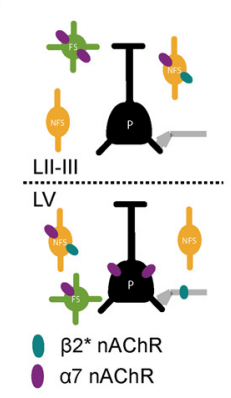

D
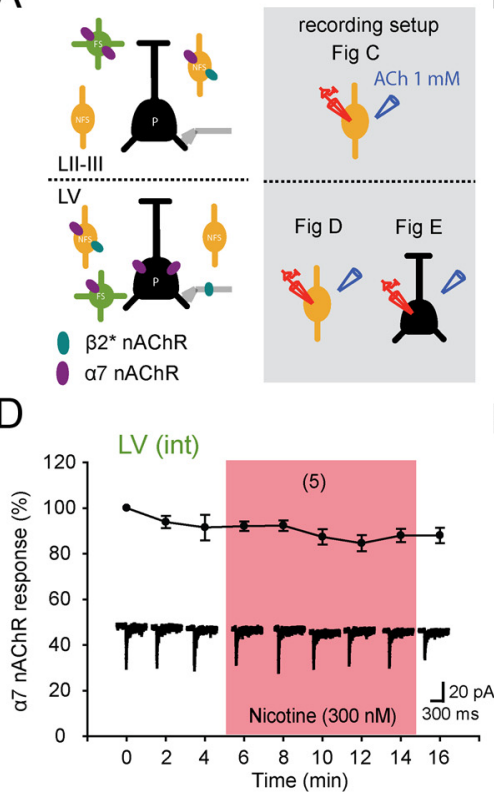

B

$\mathrm{E}$

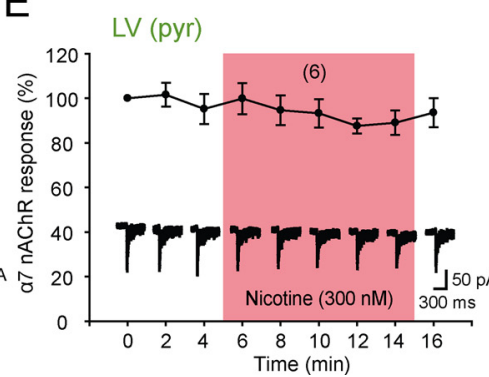

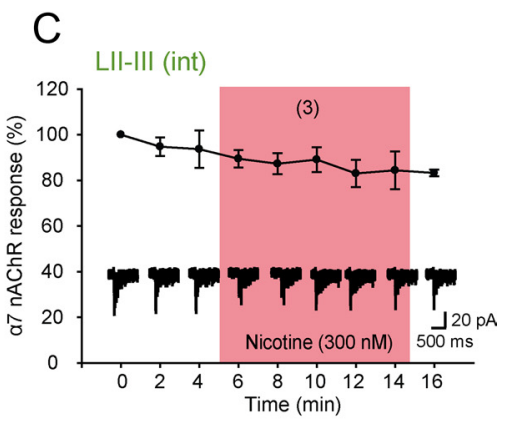

$\mathrm{F}$

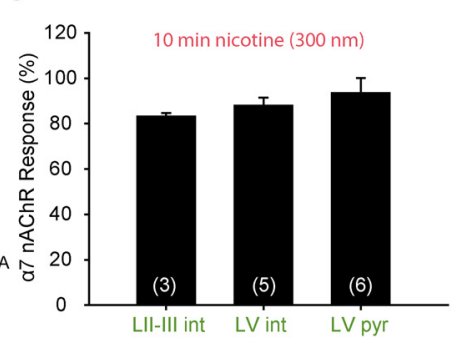

Figure 2. Smoking concentrations of nicotine do not affect $\alpha 7 \mathrm{nAChR}$ currents. $\boldsymbol{A}$, Left, nAChR modulation of PFC microcircuitry in LII-III and LV. $\beta 2 * \mathrm{nAChRs}$ and $\alpha 7 \mathrm{nAChRs}$ are indicated with turquoise and purple colored ovals. Right panel in gray shading shows the recording setup for the different experiments. $\boldsymbol{B}$, Characteristics of $\alpha 7$ nAChRs. Currents show rapid activation and desensitization kinetics and are blocked by MLA and absent in $\alpha 7$-null mice (Poorthuis et al., 2013). In gray shading a magnification of an $\alpha 7$ current is shown. $\boldsymbol{C}$, Effect of nicotine (pink shading, $300 \mathrm{~nm}, 10 \mathrm{~min}$ ) on $\alpha 7 \mathrm{nAChR}$ current responses induced by ACh (1 mm) application on juvenile LII-III interneurons. Nicotine does not interfere with a7 nAChR activation in the PFC. $\boldsymbol{D}$, Same as in $\boldsymbol{C}$ but now for interneurons in layer V. $\boldsymbol{E}$, Same as in C but now for layer V pyramidal neurons. $\boldsymbol{F}$, Summary bar graph showing the effect of smoking concentrations of nicotine on $\alpha 7$ ( 300 nm, 10 min) $\mathrm{nAChR}$ currents. Nicotine exposure did not desensitize $\alpha 7 \mathrm{nAChR}$ currents throughout the PFC (Student's $t$ test, $p=0.31, p=0.69$, and $p=0.25$ for LII-III interneurons, LV interneurons, and LV pyramidal neurons, respectively).

ACh-induced increase in frequency of spontaneous EPSCs (Fig. $3 C 1,3$; control $n=21,992 \pm 172 \%, p<0.01$, nicotine $n=11$, $340 \pm 34 \%, p<0.05$, nicotine vs control, $p<0.05$ ). This reduction was more prominent with a higher dose of nicotine (Fig. $3 C 2,3 ; n=6,118 \pm 12 \%, p=0.96$, control vs nicotine, $p<0.05)$. Together, these data show that in PFC LV, nicotine partially interferes with $\beta 2^{\star} \mathrm{nAChR}$ signaling on NFS interneurons and glutamatergic inputs received by LV pyramidal neurons.

\section{Differential desensitization of $\beta 2^{\star}$-mediated $\mathrm{nAChR}$ currents in layer VI}

Layer VI pyramidal neurons are relatively spared from desensitization because of the presence of $\alpha 5$ subunits (Bailey et al., 2010). Whether this holds true for LVI interneurons, which are also modulated by $\beta 2^{\star}$ nAChRs (Fig. $4 A$ ) (Poorthuis et al., 2013), is not known. To investigate possible differences we targeted these two cell types. A 10 min application of nicotine completely abolished $\beta 2^{*} \mathrm{nAChR}$-mediated responses to ACh application on nonfast-spiking interneurons (Fig. $4 B, C, F ; 13.1 \pm 3.4 \%$ remaining charge, $n=7, p<0.01)$. In contrast, $\beta 2^{\star}$ nAChR-mediated responses to ACh application of pyramidal neurons (Fig. $4 B$ ) did not desensitize completely (Fig. 4B, D, F; $29.1 \pm 3.1 \%$ remaining charge, $n=5, p<0.01$ ). The degree of desensitization was significantly less for LVI pyramidal neurons compared with interneurons in LVI $(p<0.01)$. During development, expression of nAChR subunits in LVI pyramidal neurons changes (Kassam et al., 2008). In the adolescent PFC, ACh-induced currents in LVI pyramidal neurons showed a similar degree of desensitization when exposed to nicotine as in the juvenile PFC (Fig. 4E,F; $33.6 \pm 8.5 \%$ remaining charge, $n=5, p<0.01$; juvenile vs adolescence, $p=0.64$ ). LVI interneurons showed significantly stronger desensitization of ACh-induced $\beta 2^{\star}$ responses than LVI pyramidal neurons (Fig. $4 F, p<0.01$ ) and LV interneurons (Fig.
$4 F, p<0.01)$. Desensitization of $\beta 2^{\star}$ nAChR-mediated AChinduced currents by nicotine was also significantly stronger in LII-III interneurons than in pyramidal neurons in LVI ( $p=$ $0.02)$. Lower nicotine levels (100 nM) also had a desensitizing effect on $\beta 2^{\star}$ responses of LVI pyramidal neurons (Fig. $4 F$; $43.21 \pm 8.5 \%$ remaining charge, $n=5, p<0.01$ ), but less compared with layer II-III interneurons $(p=0.04)$. These data show that layer-specific interference with cholinergic signaling also holds true for lower concentrations of nicotine.

\section{Involvement of $\alpha 5 \mathrm{nAChR}$ subunit explains layer-specific} interference of nicotine with cholinergic signaling

The level of desensitization of $\beta 2^{*} \mathrm{nAChR}$-mediated AChinduced currents differed in different PFC layers. Layer VI pyramidal neurons express the accessory $\alpha 5 \mathrm{nAChR}$ subunit, which protects $\beta 2^{\star} \mathrm{nAChRs}$ from complete desensitization (Kassam et al., 2008; Grady et al., 2012). We hypothesized that $\beta 2^{\star}$ nAChRs expressed by neuron types that showed stronger desensitization did not contain the $\alpha 5 \mathrm{nAChR}$ subunit. To investigate this, we first used galantamine, an allosteric modulator that potentiates $\beta 2^{\star}$ nAChRs containing $\alpha 5$ subunits, but not $\beta 2^{\star}$ nAChRs lacking the $\alpha 5$ subunit (Kassam et al., 2008; Kuryatov et al., 2008). We applied acetylcholine $(1 \mathrm{~mm})$ with a puff electrode for $30 \mathrm{~s}$ and repeated this procedure after $10 \mathrm{~min}$ exposure to galantamine ( 1 $\mu \mathrm{M}$ ) to test for possible potentiation in adolescent animals (Fig. $5 A)$. ACh-induced $\beta 2^{\star}$-mediated currents in layer II-III interneurons were not potentiated by galantamine exposure (Fig. $5 A, B ; n=6,30.4 \pm 10.1{ }^{\star} 10^{\wedge}-9$ vs $30.5 \pm 7.2^{\star} 10^{\wedge}-9 \mathrm{C}, p=$ $0.97)$. In contrast, $\beta 2^{\star} \mathrm{nAChR}$ currents in layer VI pyramidal neurons were potentiated after application of galantamine (Fig. $5 A, B ; n=10,64 \pm 12^{\star} 10^{\wedge}-9$ vs $93.2 \pm 14.6^{\star} 10^{\wedge}-9$ C, $\left.p=0.01\right)$. These data suggest that a layer-specific receptor composition of $\beta 2^{\star} \mathrm{nAChRs}$ exists in the prefrontal cortex. $\beta 2^{*} \mathrm{nAChRs}$ in layer 
A1

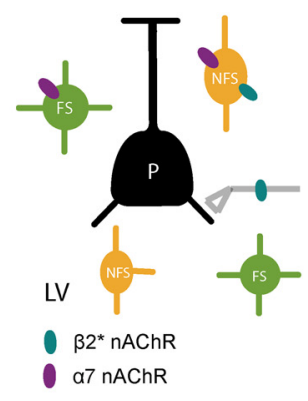

B1

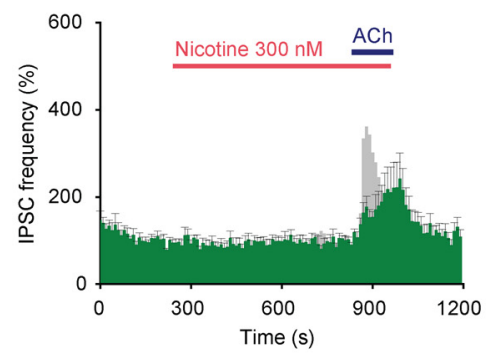

C1

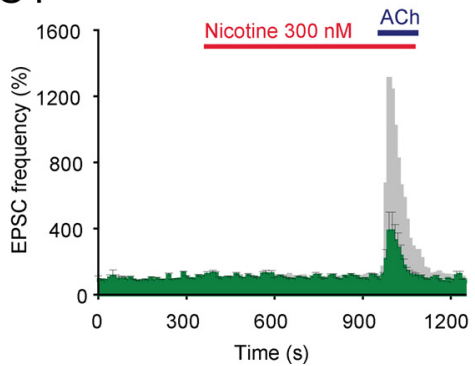

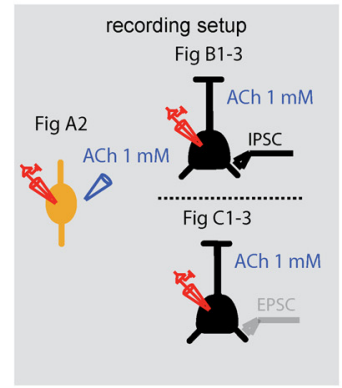

B2

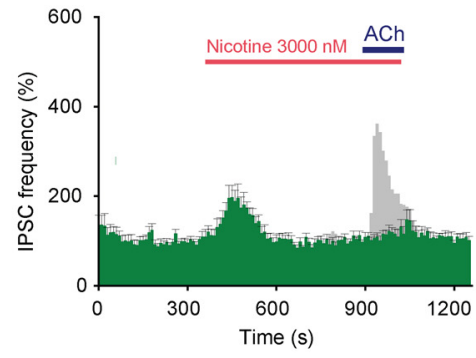

C2

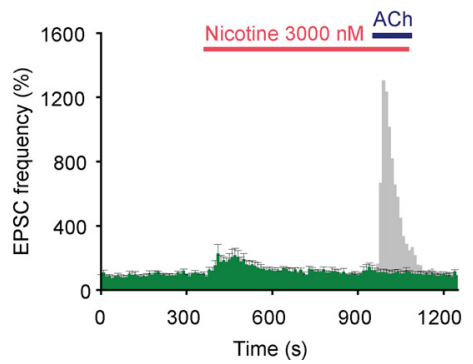

A2

A3

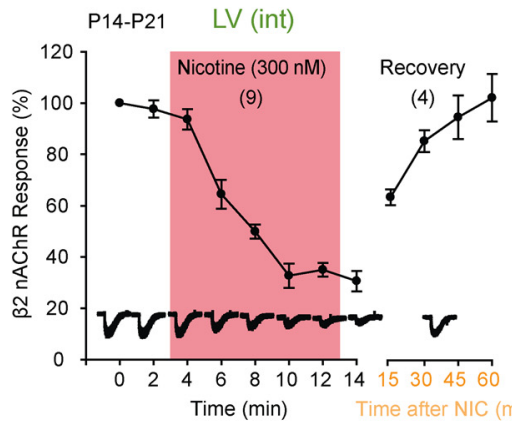

B3

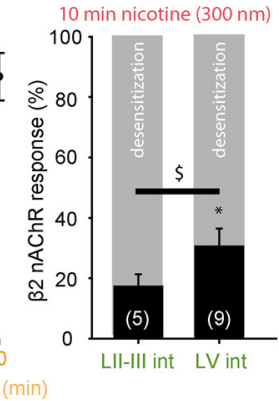

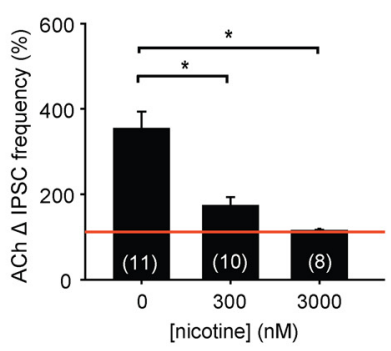

C3

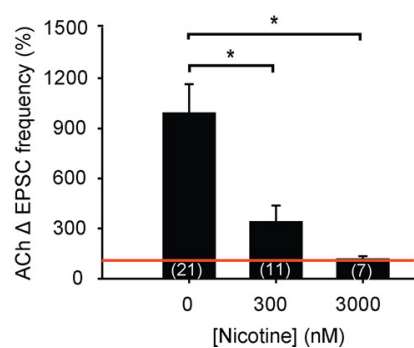

Figure 3. Partial interference of nicotine with $\beta 2^{*} n A C h R$-mediated currents in LV.A1, Microcircuitry showing nAChR distribution in layer V of the PFC. On the right, in gray shading, the recording setup for Figure 3A-C is shown. A2, Average current responses of juvenile LV NFS interneurons to local ACh (1 mm) application during bath exposure to nicotine ( $300 \mathrm{~nm}, 10 \mathrm{~min}$, pink shading). ACh-induced currents are not completely abolished after $10 \mathrm{~min}$. Currents remain smaller for up to $45 \mathrm{~min}$ when nicotine is washed out of the bath. $\mathbf{A}$, Summary histogram showing the desensitizing effect of nicotine on ACh-induced $\beta 2^{*} \mathrm{nAChR}$ responses. Nicotine significantly interferes with $\beta 2^{*} \mathrm{nAChR}$ currents in LV NFS-interneurons $\left({ }^{*} p<0.01\right)$, but the desensitization is less compared with LII-III (Student's ttest, ${ }^{\$} p<0.05$ ). B1, Histogram showing nicotine only partially interferes with the effect of ACh on inhibitory transmission to layer V pyramidal neurons. Response without nicotine is shown in gray. B2, Same experiment as in $\boldsymbol{A}$, but for $3000 \mathrm{~nm}$ nicotine. $\boldsymbol{B}$, Summary showing the effect of nicotine on the ACh-induced increase of inhibitory transmission to layer $V$ pyramidal neurons $(300 \mathrm{~nm}, p<0.01 ; 3000 \mathrm{~nm}, p<0.01)$. C1, Histogram showing that nicotine strongly interfered with the effect of ACh on glutamatergic transmission to layer $V$ pyramidal neurons. Response without nicotine is shown in gray. (2), Same experiment as in $\mathbf{A}$, but for $3000 \mathrm{~nm}$ nicotine. C3, Summary bar graph showing the desensitizing effect of nicotine on the ACh-induced increase of excitatory transmission to layer V pyramidal neurons ( 300 and $3000 \mathrm{~nm}, p<0.01$ ).

II-III do not contain $\alpha 5$ subunits, whereas $\beta 2^{\star}$ nAChRs on layer VI pyramidal neurons do contain $\alpha 5$ subunits.

We next tested the hypothesis that the nAChR $\alpha 5$ subunit determines the different layer-specific degree of desensitization. We targeted layer II-III interneurons and layer VI pyramidal neurons in the PFC of adolescent $\alpha 5$-null mice and their wildtype littermates (P34-P43). LVI pyramidal neurons lacking the $\alpha 5$ subunit showed a faster and stronger degree of desensitization of ACh-induced currents by nicotine than wild-type LVI neurons (Fig. 6A). After 2 min of exposure to nicotine, desensitization of ACh-responses was significantly stronger in the $\alpha 5$ knock-out neurons compared with wild-type neurons (Fig. $6 C$; wild type vs knock-out; $75.2 \pm 2.9$ vs $53.7 \pm 5.9, p=0.01$ ). After $10 \mathrm{~min}, \beta 2^{*}$ nAChRs of layer VI pyramidal neurons were completely desensitized, while pyramidal neurons in wild-type mice remained partially available for ACh activation (Fig. 6C; $23.9 \pm$ $2.1 \%$ vs $8.1 \pm 4.5 \%, p=0.01)$. In layer II-III, however, the degree of desensitization was not affected by the absence of the $\alpha 5$ subunit at any time point (Fig. $6 \mathrm{~B}$; wild type vs knock-out; $54.9 \pm$ $10 \%$ vs $65.4 \pm 6.1 \%, p=0.40$ after 2 min nicotine and $15.0 \pm$ $4.9 \%$ vs $11.6 \pm 5.4 \%, p=0.65$ after $10 \mathrm{~min}$ of nicotine). These data confirm that $\alpha 5$ subunits are not expressed by LII-III neurons and therefore show a stronger degree of desensitization of $\beta 2^{*} \mathrm{nAChR}$ currents by smoking concentrations of nicotine.

\section{Nicotine limits nAChR-mediated neuronal activation to layer VI pyramidal neurons}

Nicotine strongly affects cholinergic activation of $\beta 2^{\star} \mathrm{nAChRs}$ in a layer-specific manner. Therefore, we asked the question to what extent neuronal activation by ACh in the different layers would be affected by the presence of smoking nicotine concentrations. To test this, we used two-photon imaging of fura- 2 loaded PFC slices and bath applied nicotine $(300 \mathrm{nM})$ for $10 \mathrm{~min}$ before bath applying ACh (Fig. 7A). Bath application of ACh mainly affects action potential firing in neurons by activating $\beta 2^{*} \mathrm{nAChRs}$ (Poorthuis et al., 2013). Nicotine application increased neuronal 
A

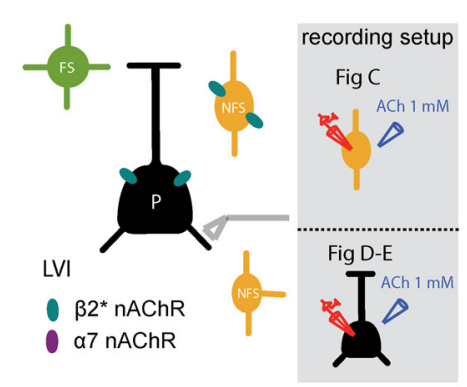

B

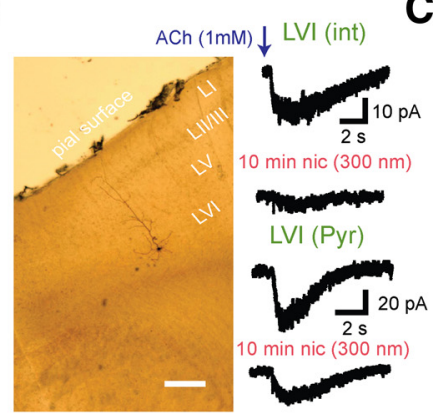

C

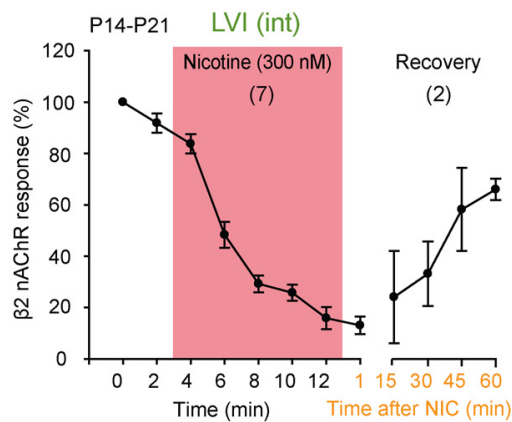

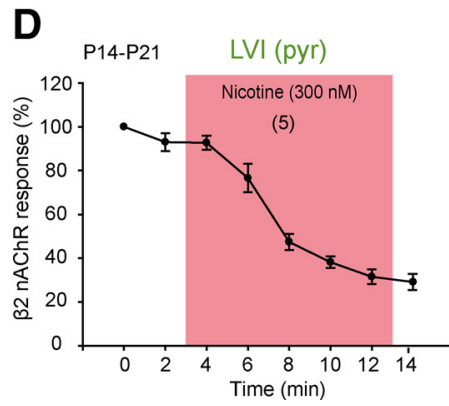
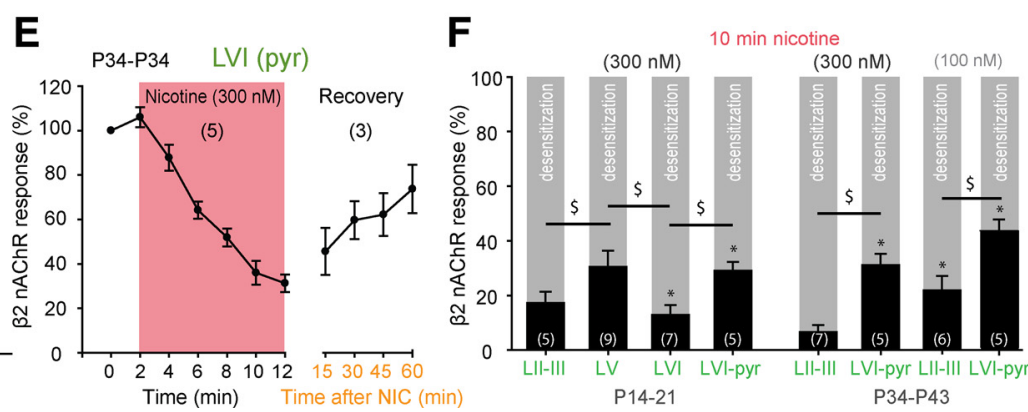

Figure 4. Differential desensitization of $\beta 2 *$-mediated $\mathrm{nAChR}$ currents in layer VI. $A, \mathrm{nAChR}$ modulation of layer VI microcircuitry. On the right, in gray shading, the recording setup for the different experiments is displayed. $\boldsymbol{B}$, Morphological staining of an adolescent LVI pyramidal neuron. Scale bar, $250 \mu \mathrm{m}$. On the right example traces are shown of acetylcholine-induced $\beta 2^{*} \mathrm{nAChRs}$ of layer VI neurons before and after exposure to nicotine ( $300 \mathrm{~nm}, 10 \mathrm{~min}$ ). C, Average current responses of $\beta 2^{*} \mathrm{nAChR}$ currents during baseline and during application of nicotine ( $300 \mathrm{~nm}, 10 \mathrm{~min}$ ). Nicotine strongly reduces current responses of LVI interneurons. $\boldsymbol{D}$, Same as in $\boldsymbol{C}$ but now for LVI pyramidal neurons. $\boldsymbol{E}$, Same as in $\boldsymbol{D}$ but now for adolescent mice. $\boldsymbol{F}$, Summary bar graph showing desensitization of $\beta 2{ }^{*} \mathrm{nAChRs}$ in the PFC. nAChR currents in LVI interneurons were strongly desensitized (Student's $t$ test, $p<0.01$ ) in contrast to nAChR currents in LVI pyramidal neurons, which remain partially available for activation $\left({ }^{\$} p<0.01\right)$. $\mathrm{nAChR}$ currents in adolescent layer VI pyramidal neurons desensitized $(p<0.01)$ to a similar degree as in juvenile mice $(p=0.64)$. $\beta 2^{*} \mathrm{nAChRs}$ currents of LVI interneurons desensitized more than LV interneurons $\left({ }^{5} p<0.01\right)$. In addition, $\beta 2^{*}$ nAChR currents of LII-III interneurons desensitized stronger than layer VI pyramidal neurons $\left({ }^{\$} p=0.02\right)$. 100 nm nicotine also strongly desensitized $\beta 2^{*}$ nAChRs of adolescent LVI pyramidal neurons ( $\left.{ }^{*} p<0.01\right)$, but less compared with layer II-III $\left({ }^{\$} p=0.04\right)$.

A

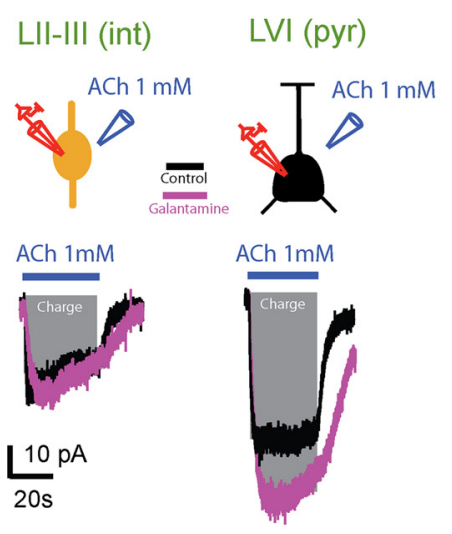

B

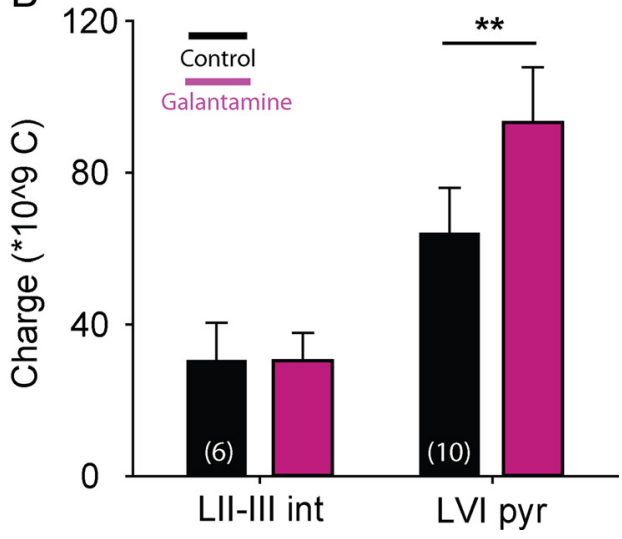

Figure 5. Galantamine does not potentiate LII-III $\beta 2^{*} \mathrm{nAChRs}$. A, The effect of galantamine on $\beta 2^{*} \mathrm{nAChRs}$ was tested on LII-III interneurons and LVI pyramidal neurons. ACh was applied for $30 \mathrm{~s}$ before (black traces) and after galantamine ( $1 \mu \mathrm{M}$, pink traces) was washed in for $10 \mathrm{~min}$. The bottom show the average response for LII-III NFS interneurons $(n=6)$ and layer VI pyramidal neurons $(n=10)$. The effect on the ACh-induced currents was assessed by calculating the total charge during the $30 \mathrm{~s}$ ACh application. $\boldsymbol{B}$, Galantamine potentiates $\beta 2^{*} \mathrm{nAChR}$ currents on layer VI pyramidal neurons (Student's $t$ test, $p<0.01$ ), but not in LII-III interneurons $(p=0.97)$.

activity in layer $\mathrm{V}$ and VI of the PFC (layer V, Fisher's LSD post hoc test, $p<0.01$, layer VI, $p=0.04$; Fig. $7 B, C)$. In LII-III, after application of nicotine, subsequent application of ACh did not increase neuronal activity and the number of activated cells per slice was similar as control conditions (Fig. $7 C, D, p=0.82$ ). In layer $\mathrm{V}$, neurons were activated $(p<0.01)$ by low concentrations nicotine and subsequent application of ACh slightly increased this activity $(p<0.05$, Fig. $7 C, D)$. In layer VI, application of ACh in the presence of nicotine prominently increased neuronal ac- tivity $(p<0.001$, Fig. $7 C, D)$. To address the question whether the remaining activation of neurons in deep layers were pyramidal neurons or interneurons, we identified from the high resolution $z$-stacks imaged neurons as pyramidal neurons or interneurons (Fig. 7E). Nicotine application strongly reduced activation of interneurons in the PFC $(p=0.039$, Fig. $7 G$ ). The effect of nicotine on pyramidal neurons was layer specific. Layer VI pyramidal neurons were the only cell type that still showed an increase in activation upon ACh application in the presence of nicotine $(p<0.001$, Fig. $7 F)$. Pyramidal neurons in layer II-III and layer $\mathrm{V}$ and PFC interneurons showed no significant subsequent activation by ACh (Fig. $7 F, G$, $p>0.05)$. Thus, nicotine concentrations experienced by smokers results in the loss of ACh modulation of pyramidal and interneurons in LII-III and LV. In the presence of nicotine, only layer VI pyramidal neurons will respond to fast ACh signaling.

To test whether the remaining activation of layer VI neurons depended on the presence of the $\alpha 5$ subunit we imaged slices from $\alpha 5$ knock-out and wild-type littermates. As shown in the previous experiment, there was a stronger activation of layer VI compared with layer $\mathrm{V}$ in wild-type mice (Fig. $7 \mathrm{H}, \mathrm{p}<0.01$ ). In $\alpha 5$-null mice, ACh did not increase activity in layer VI in the presence of nicotine (Fig. $7 H, p=0.64$ ), and ACh-induced activ- 
A

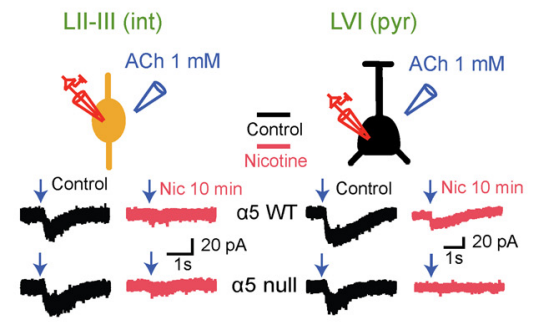

B

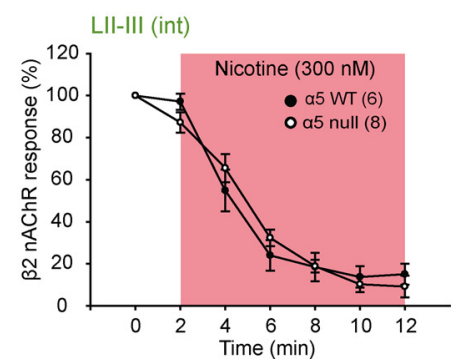

C

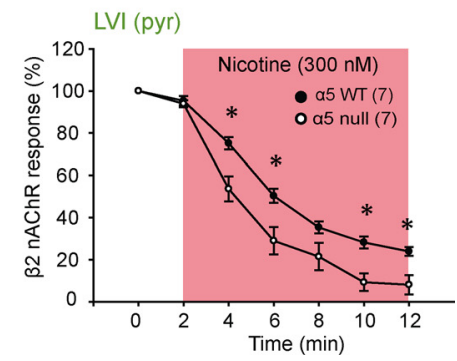

Figure 6. Expression of a $5 \mathrm{nAChR}$ subunits explains layer-specific desensitization of $\beta 2^{*} \mathrm{nAChR}$ currents by nicotine. $A$, Recording setup of experiment and example traces of $\mathrm{nAChR}$ currents in PFC LVI pyramidal neurons and in LII-III interneurons of wild-type and $\alpha$-null littermates before and after exposure to nicotine ( $10 \mathrm{~min}, 300 \mathrm{~nm}) . \boldsymbol{B}$, Average response of $\beta 2^{*} \mathrm{nAChRs}$ on LII-III NFS interneurons to ACh stimulation ( $1 \mathrm{~mm}$ ) in wild-type and $\alpha 5$-null adolescent mice. The degree of desensitization was not different for any time point in the absence of the $\alpha 5$ subunit $(p>0.05$ for all time points). C, Average response of $\beta 2^{*} \mathrm{nAChRs}$ on LVI pyramidal neurons to ACh stimulation ( $\left.1 \mathrm{~mm}\right)$ in wild-type and $\alpha 5$ knock-out adolescent mice. The degree of desensitization in the absence of the $\alpha 5$ subunit was faster (at 2 min, Student's $t$ test, $p=0.01$ ) and stronger (at $10 \mathrm{~min}, p=0.01$ ).

ity was strongly reduced in PFC layer VI of $\alpha 5$-null mice compared with wild-type mice (Fig. $7 H, p<0.01$ ). Hence, these data show that exposure to low concentrations of nicotine limits neuronal activation by cholinergic signaling through $\beta 2^{*} \mathrm{nAChRs}$ in the PFC to layer VI pyramidal neurons that express $\alpha 5$ subunits.

\section{Discussion}

In this study we showed that nicotine strongly reduces cholinergic activation of the PFC network and that this effect is cell type and layer specific and depends on $\mathrm{nAChR}$ subunit expression. Cholinergic responses mediated by $\beta 2^{\star} \mathrm{nAChRs}$ desensitize after 10 min exposure to smoking concentrations of nicotine (300 nM). In contrast, $\alpha 7 \mathrm{nAChRs}$ remained available for cholinergic signaling throughout the PFC circuitry. $\beta 2^{*} \mathrm{nAChR}$ currents in interneurons in LII-III and LVI were completely desensitized by nicotine. $\beta 2^{\star} \mathrm{nAChR}$ currents in LV interneurons were less compromised by nicotine exposure, just as $\beta 2^{\star} \mathrm{nAChR}$ currents in LVI pyramidal neurons. Also, $\beta 2^{\star} \mathrm{nAChRs}$ on thalamic terminals activating layer $\mathrm{V}$ pyramidal neurons were strongly desensitized by nicotine. A similar degree of desensitization was found in adolescent animals, a developmental time period in which the $\mathrm{PFC}$ is vulnerable for long-term adaptations induced by nicotine (Counotte et al., 2011b; Goriounova and Mansvelder, 2012a). Layer-dependent desensitization of $\beta 2^{\star} \mathrm{nAChR}$ currents in adolescent mice was caused by the presence or absence of $\alpha 5$ subunits. In conclusion, nicotine greatly reduced cholinergic activation and altered the balance of cholinergic signaling through nAChRs in the PFC neuronal network depending on nAChR subunit composition.

Cigarette smoking leads to a prolonged presence of nicotine levels in the brain that reach 300-600 nM for minutes (Matta et al., 2007). Smoking of one cigarette leads to nearly complete $\beta 2^{*}$ $\mathrm{nAChR}$ receptor saturation in humans (Brody et al., 2006). Sustained exposure to low levels of nicotinic agonists rapidly desensitizes nicotinic receptors (Fenster et al., 1997; Picciotto et al., 2008). Whether smoking nicotine concentrations influence nAChRs by desensitization in circuits involved in attention behavior was not known. We find that nicotine rapidly decreases responsiveness of $\beta 2^{*} \mathrm{nAChRs}$ in the PFC, while leaving $\alpha 7$ $\mathrm{nAChRs}$ intact. Because of coapplication of ACh and nicotine, we cannot rule out agonist competition at the receptor binding site, however, the persistent reduced responsiveness of $\beta 2^{\star} \mathrm{nAChRs}$ $(>45 \mathrm{~min})$ after the presence of nicotine suggests that nicotinic receptors indeed were desensitized. An alternative explanation could be that nicotinic receptors were internalized (St. John and Gordon, 2001). However, the responses did recover after an hour, suggesting recovery from desensitization. The subunit specificity of receptor desensitization observed is similar to that seen in the ventral tegmental area where nicotine desensitizes $\beta 2^{\star}$ nAChRs on GABAergic interneurons, but not $\alpha 7$ nAChRs on glutamatergic terminals and dopamine neurons (Mansvelder et al., 2002; Wooltorton et al., 2003). Hence, whereas $\alpha 7$ nAChRs display rapid desensitization kinetics after being activated by rapid increases in agonists, they do not desensitize upon the prolonged presence of smoking concentrations of nicotinic agonist. These separate processes, referred to as "classical" and "highaffinity" desensitization (Giniatullin et al., 2005), thus operate in the PFC as well suggesting that $\alpha 7 \mathrm{nAChRs}$ remain available for activation by fast cholinergic transients (Parikh et al., 2007).

The desensitizing properties of $\beta 2^{\star} \mathrm{nAChRs}$ are heterogeneous. The accessory $\alpha 5$ subunit plays a critical role in determining whether $\beta 2^{*}$ nAChRs remain available for cholinergic signaling (Bailey et al., 2010; Grady et al., 2012). In the cortex, $\alpha 5$ subunits are preferentially expressed by neurons in deep layers (Winzer-Serhan and Leslie, 2005). Expression of $\alpha 5$ subunits is lower in superficial layers (Winzer-Serhan and Leslie, 2005), but still $\alpha 5$ could be located on NFS interneurons, which constitute a small number of cells in the PFC modulated by $\beta 2^{*}$ nAChRs (Poorthuis et al., 2013). In the PFC, $\alpha 5$ and $\beta 2$ subunits coassemble in LVI pyramidal neurons (Bailey et al., 2010). We find that the presence of $\alpha 5$ subunits does not extend to NFS interneurons in layer VI, which show a higher and complete degree of desensitization after nicotine exposure. However, it has been reported that some cortical interneurons express $\beta 2$ and $\alpha 4$ subunits in combination with $\alpha 5$ subunits (Porter et al., 1999). We find that $\beta 2$-mediated responses in LV interneurons show similar levels of desensitization as responses by LVI pyramidal neurons, suggesting that they may also express $\alpha 5$ subunits.

Exposure to nicotine during adolescence has perturbing effects on attention performance in later life (Counotte et al., 2011a). We investigated the effect of nicotine on cholinergic signaling in the juvenile (P14-P21) and adolescent mouse (P34$\mathrm{P} 43)$. Although $\beta 2^{*}$, but not $\alpha 7, \mathrm{nAChR}$ receptor expression changes with age (Kassam et al., 2008; Counotte et al., 2012), we find similar percentage of $\beta 2^{\star} \mathrm{nAChR}$ desensitization in both age groups. Receptor desensitization and strong interference with cholinergic signaling by concentrations of nicotine experienced by smokers may be the first step in a cascade of events leading to molecular, cellular, and functional changes in the PFC. After adolescent nicotine exposure, the nicotinic receptor subunits $\alpha 4$ and $\beta 2$ are strongly upregulated, whereas $\alpha 7$ and $\alpha 5$ subunit 

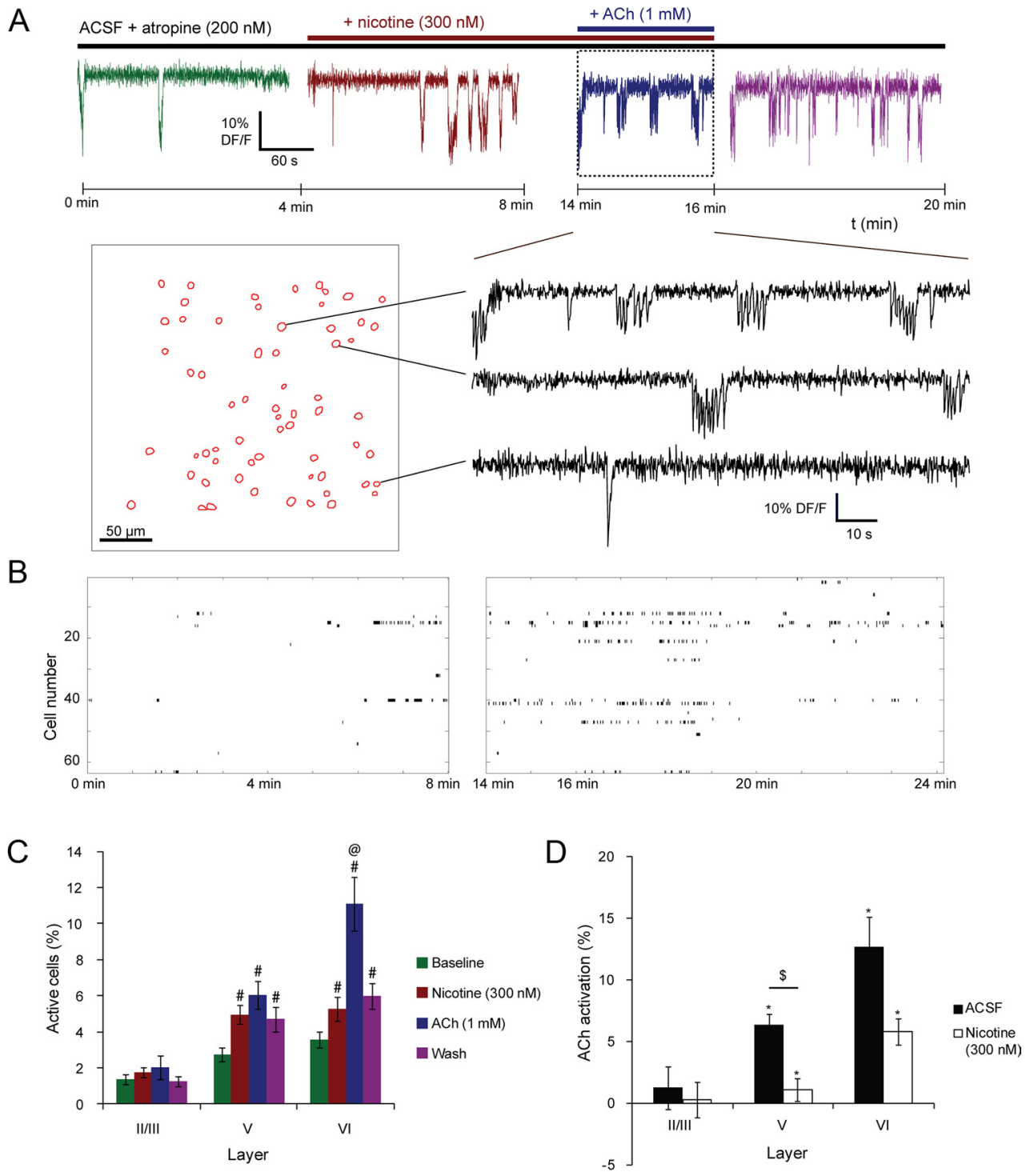

E

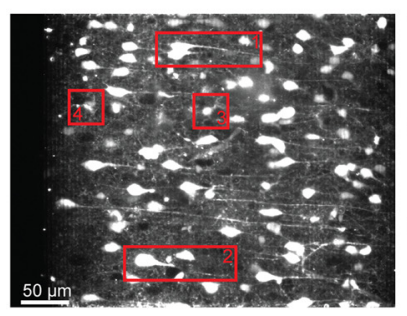

G

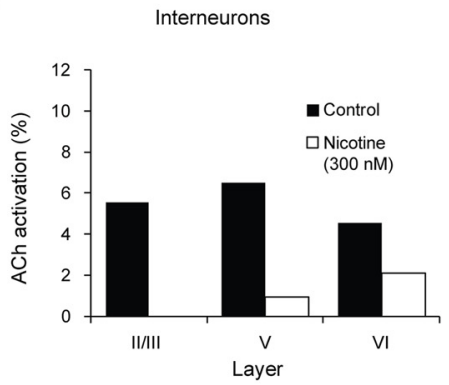

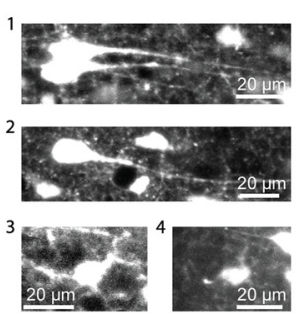

$\mathrm{F}$

Pyramidal neurons

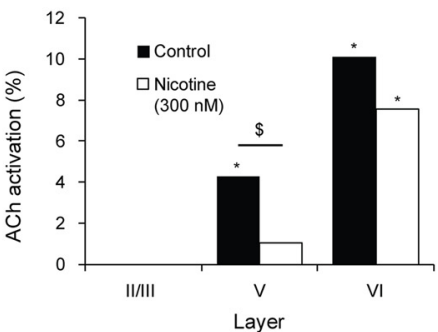

$\mathrm{H}$

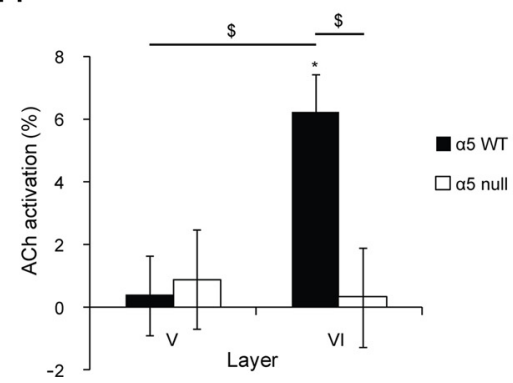

Figure 7. Nicotine limits nAChR-mediated neuronal activation to LVI pyramidal neurons. A, Example of an experiment using network calcium imaging. Contours of Fura2-AM loaded neurons were detected after which traces from these neurons were extracted. Shown are calcium events before, during, and after the application of nicotine (300 nM) and ACh (Figure legend continues.) 
expression remains unchanged (Counotte et al., 2012). One may hypothesize that the strong desensitization of receptors containing the $\beta 2$ subunit induces the upregulation following adolescent exposure as an adaptive strategy to maintain cholinergic signaling through these receptors. Similarly, the lack of desensitization of $\alpha 7 \mathrm{nAChRs}$ and the limited desensitization of $\alpha 5$ containing nAChRs do not trigger the upregulation. Indeed, after repeated nicotine exposure during adolescence, cholinergic control over GABAergic inhibition in LII-III is increased (Counotte et al., 2012), suggesting an augmentation of functional nicotinic receptors. Whether nAChR upregulation in the PFC after nicotine exposure during adolescence is cell type and layer specific remains to be investigated. An increase in number of nAChRs at neuronal surfaces after prolonged nicotine exposure is probably mediated by several posttranslational mechanisms (Goriounova and Mansvelder, 2012a; Govind et al., 2012). Ultimately, compensatory mechanisms secondary to altered cholinergic signaling might lead to reduced mGluR levels and consequently alters synaptic learning rules and attention behavior (Counotte et al., 2011a, b; Goriounova and Mansvelder, 2012b).

Although acute exposure to nicotine has been shown to enhance attention performance in rats under some circumstances (Hahn et al., 2003; Levin et al., 2006), nicotine has been found to decrease attention performance in mice (Bailey et al., 2010). Our integrative network approach shows that nicotine concentrations seen by smoking limits nAChR-induced action potential firing to layer VI pyramidal neurons. What could be the functional consequence of this shift in cortical computation? Fast cholinergic transients are important for cue detection and attention behavior (Parikh et al., 2007, 2010). Nicotine exposure strongly abolishes control over GABAergic circuitry in the PFC. Nicotinic receptor activation of interneurons has been shown to modulate pyramidal neuron activity and increases the threshold for induction of spike-timing dependent synaptic plasticity in cortex and hippocampus (Ji et al., 2001; Couey et al., 2007). Cholinergic signaling might therefore increase the signal-to-noise ratio in the PFC. When nicotine is present in the PFC, this mechanism is absent

\footnotetext{
(Figure legend continued.) (1 mM). B, Rasterplot of the activity of all neurons in a slice during the experiment. $\boldsymbol{C}$, Average percentage of active cells per slice per minute. Nicotine $(300 \mathrm{~nm})$ increased activity in layers V and VI (Fisher's LSD post hoc test; layer V: $p=0.0012$; layer VI: $p=$ 0.038 ; significant effects indicated with \#) but not in layer II/III ( $p=0.71$ ). Subsequent application of ACh (1 mm) only resulted in a significant increase of the percentage of active cells in layer VI ( $p<0.0001$; layer II/III: $p=0.82$; layer V: $p=0.11$; significant effect indicated with @). D, Nicotine preapplication (300 $\mathrm{nm})$ reduced the activation by subsequent ACh $(1 \mathrm{~mm})$ application (all layers: $p=0.002$ ). This effects was significant for layerV ( $p=0.00004$ ) but not for layer II/III $(p=0.4)$ or layer VI $(p=0.09)$. Despite this, there remained a significant activation in layer V and VI (aCSF layer V: $p=0.000001$; aCSF layer VI: $p=0.001$; nicotine layer $\mathrm{V}: p=0.032$; nicotine layer VI: $p=0.035$ ), whereas activation in layer II/III remained nonsignificant (aCSF layer II/III: $p=0.22$; nicotine layer II/III: $p=0.74$ ). $\boldsymbol{E}$, Projection of $z$-stack showing the morphology of imaged neurons. $F$, Nicotine $(300 \mathrm{~nm})$ desensitized the response to ACh (1 mM) in layer V pyramidal neurons (LV vs LVI: $p=0.0036$; without nicotine: $p=0.0019$; with nicotine preapplication: $p=0.08$ ), whereas layer VI pyramidal neurons remain responsive (LV vs LVI: $p=0.66$; without nicotine: $p<0.001$; with nicotine preapplication: $p<0.001$ ). G, Nicotine $(300 \mathrm{~nm})$ desensitized the responses of interneurons to $\mathrm{ACh}(1 \mathrm{~mm})$ throughout all layers $(p=0.039)$. $\boldsymbol{H}$, The absence of desensitization of layer VI pyramidal neurons is dependent on the $\alpha 5 \mathrm{nAChR}$ subunit. Mice lacking this subunit have a desensitized response to ACh (1 $\mathrm{mm}$ ) after nicotine preapplication in both layer V and layer VI (layer V: $p=0.40$; layer VI: $p=$ 0.64 ), whereas their WT littermate controls still show significant activation by ACh in layer VI (layer V: $p=0.55$; layer VI: $p=0.004)$. The interaction between genotype and layer was significant ( $p=0.027$ ) and the activation in layer VI of the littermate controls was significantly bigger than the activation in layer VI of the $\alpha 5$-null mice ( $p=0.004)$ and in layer V of the WT animals $(p=0.001)$
}

and might lead to compromised information processing. At the behavioral level, a lack of functional $\beta 2^{\star} \mathrm{nAChRs}$ has been shown to lead to a hyperactive medial prefrontal cortex and altered social and exploratory behavior (Avale et al., 2011; Bourgeois et al., 2012), suggesting that the PFC network is disinhibited in the absence of this receptor. Supporting this, genetic deletion of $\beta 2^{\star}$ nAChRs also leads to impaired attention behavior, which depends on $\beta 2$ subunits in the medial PFC (Guillem et al., 2011).

Nicotine-induced desensitization also reduced nAChRmediated control over excitatory elements in layer V and VI. In the absence of nicotine, activity of pyramidal neurons in layer $\mathrm{V}$ is strongly enhanced by glutamate release induced by $\beta 2^{*} \mathrm{nAChRs}$ on axonal terminals originating in the medial dorsal thalamus (Lambe et al., 2003; Parikh et al., 2008; Poorthuis et al., 2013). The reduction in cholinergic nAChR-mediated control over this circuitry in the presence of nicotine might compromise cueinduced cholinergic transients and hence signal detection during attentional tasks (Parikh et al., 2010). Cholinergic induced activity of layer VI pyramidal neurons is also reduced. Part of the output neurons in layer VI form a thalamocortical loop (Kassam et al., 2008) and are important for regulating sensory presentations in the cortex (Olsen et al., 2012). Therefore, a decrease in cholinergic control of this circuitry might interfere with optimal attention performance (Bailey et al., 2010). In conclusion, nicotine leads to strong interference with cholinergic control over $\beta 2^{*}$ $\mathrm{nAChRs}$ in the PFC that might compromise attention behavior in the short term, and leads to maladaptive changes of PFC circuitry that leads to altered attention behavior in the long term.

\section{References}

Avale ME, Chabout J, Pons S, Serreau P, De Chaumont F, Olivo-Marin J-C, Bourgeois J-P, Maskos U, Changeux JP, Granon S (2011) Prefrontal nicotinic receptors control novel social interaction between mice. FASEB journal 25:2145-2155. CrossRef Medline

Bailey CD, De Biasi M, Fletcher PJ, Lambe EK (2010) The nicotinic acetylcholine receptor alpha5 subunit plays a key role in attention circuitry and accuracy. J Neurosci 30:9241-9252. Medline

Bourgeois JP, Meas-Yeadid V, Lesourd AM, Faure P, Pons S, Maskos U, Changeux JP, Olivo-Marin JC, Granon S (2012) Modulation of the mouse prefrontal cortex activation by neuronal nicotinic receptors during novelty exploration but not by exploration of a familiar environment. Cereb Cortex 22:1007-1015. CrossRef Medline

Brody A, Mandelkern MA, London ED, Olmstead RE, Farahi J, Scheibal D, Jou J, Allen V, Tiongson E, Chefer SI, Koren AO, Mukhin AG (2006) Cigarette smoking saturates brain $\alpha 4 \beta 2$ nicotinic acetylcholine receptors. Arch Gen Psychiatry 63:907-915. CrossRef Medline

Couey JJ, Meredith RM, Spijker S, Poorthuis RB, Smit AB, Brussaard AB, Mansvelder HD (2007) Distributed network actions by nicotine increase the threshold for spike-timing-dependent plasticity in prefrontal cortex. Neuron 54:73-87. CrossRef Medline

Counotte DS, Goriounova NA, Li KW, Loos M, van der Schors RC, Schetters D, Schoffelmeer AN, Smit AB, Mansvelder HD, Pattij T, Spijker S (2011a) Lasting synaptic changes underlie attention deficits caused by nicotine exposure during adolescence. Nat Neurosci 14:417-419. CrossRef Medline

Counotte DS, Smit AB, Pattij T, Spijker S (2011b) Development of the motivational system during adolescence, and its sensitivity to disruption by nicotine. Dev Cogn Neurosci 1:430-443. CrossRef Medline

Counotte DS, Goriounova NA, Moretti M, Smoluch MT, Irth H, Clementi F, Schoffelmeer AN, Mansvelder HD, Smit AB, Gotti C, Spijker S (2012) Adolescent nicotine exposure transiently increases high-affinity nicotinic receptors and modulates inhibitory synaptic transmission in rat medial prefrontal cortex. FASEB J 26:1810-1820. CrossRef Medline

Currie C, Nic Gabhainn S, Godeau E, Roberts C, Smith R, Currie D, Pickett W, Richter M, Morgan A, Barnekow V (eds) (2008) Inequalities in young people's health: HBSC international report from the 2005/06 Survey. In: Health policy for children and adolescents, No. 5. Copenhagen: WHO Regional Office for Europe. 
Escobedo LG, Marcus SE, Holtzman D, Giovino GA (1993) Sports participation, age at smoking initiation, and the risk of smoking among US high school students. JAMA 269:1391-1395. CrossRef Medline

Fenster CP, Rains MF, Noerager B, Quick MW, Lester RA (1997) Influence of subunit composition on desensitization of neuronal acetylcholine receptors at low concentrations of nicotine. J Neurosci 17:5747-5759. Medline

Giniatullin R, Nistri A, Yakel JL (2005) Desensitization of nicotinic ACh receptors: shaping cholinergic signaling. Trends Neurosci 28:371-378. CrossRef Medline

Gogtay N, Giedd JN, Lusk L, Hayashi KM, Greenstein D, Vaituzis AC, Nugent TF, Herman DH, Clasen LS, Toga AW, Rapoport JL, Thompson PM (2004) Dynamic mapping of human cortical development during childhood through early adulthood. Proc Natl Acad Sci U S A 101:8174-8179. CrossRef Medline

Goriounova NA, Mansvelder HD (2012a) Nicotine exposure during adolescence alters the rules for prefrontal cortical synaptic plasticity during adulthood. Front Synaptic Neurosci 4:3. CrossRef Medline

Goriounova NA, Mansvelder HD (2012b) Nicotine exposure during adolescence leads to short- and long-term changes in spike timing-dependent plasticity in rat prefrontal cortex. J Neurosci 32:10484-10493. CrossRef Medline

Govind AP, Walsh H, Green WN (2012) Nicotine-induced upregulation of native neuronal nicotinic receptors is caused by multiple mechanisms. J Neurosci 32:2227-2238. CrossRef Medline

Grady SR, Wageman CR, Patzlaff NE, Marks MJ (2012) Low concentrations of nicotine differentially desensitize nicotinic acetylcholine receptors that include $\alpha 5$ or $\alpha 6$ subunits and that mediate synaptosomal neurotransmitter release. Neuropharmacology 62:1935-1943. CrossRef Medline

Groenewegen HJ, Uylings HB (2000) The Prefrontal cortex and in the integration of sensory, limbic and autonomic information. Prog Brain Res 126:3-28. Medline

Guillem K, Bloem B, Poorthuis RB, Loos M, Smit AB, Maskos U, Spijker S, Mansvelder HD (2011) Nicotinic acetylcholine receptor $\beta 2$ subunits in the medial prefrontal cortex control attention. Science 333:888-891. CrossRef Medline

Hahn B, Shoaib M, Stolerman IP (2003) Involvement of the prefrontal cortex but not the dorsal hippocampus in the attention-enhancing effects of nicotine in rats. Psychopharmacology 168:271-279. CrossRef Medline

Ji D, Lape R, Dani JA (2001) Timing and location of nicotinic hippocampal synaptic plasticity. Neuron 31:131-141. CrossRef Medline

Kassam SM, Herman PM, Goodfellow NM, Alves NC, Lambe EK (2008) Developmental excitation of corticothalamic neurons by nicotinic acetylcholine receptors. J Neurosci 28:8756-8764. CrossRef Medline

Kuryatov A, Onksen J, Lindstrom J (2008) Roles of accessory subunits in $\alpha 4$ $\beta 2$ * nicotinic receptors. Mol Pharmacol 74:132-143. CrossRef Medline

Lambe EK, Picciotto MR, Aghajanian GK (2003) Nicotine induces glutamate release from thalamocortical terminals in prefrontal cortex. Neuropsychopharmacology 28:216-225. CrossRef Medline

Levin ED, McClernon FJ, Rezvani AH (2006) Nicotinic effects on cognitive function: behavioral characterization, pharmacological specification, and anatomic localization. Psychopharmacology 184:523-539. CrossRef Medline

Mansvelder HD, Keath JR, McGehee DS (2002) Synaptic mechanisms underlie nicotine-induced excitability of brain reward areas. Neuron 33: 905-919. CrossRef Medline

Matta SG, Balfour DJ, Benowitz NL, Boyd RT, Buccafusco JJ, Caggiula AR, Craig CR, Collins AC, Damaj MI, Donny EC, Gardiner PS, Grady SR,
Heberlein U, Leonard SS, Levin ED, Lukas RJ, Markou A, Marks MJ, McCallum SE, Parameswaran N, et al. (2007) Guidelines on nicotine dose selection for in vivo research. Psychopharmacology 190:269-319. CrossRef Medline

Miller EK (2000) The prefrontal cortex and cognitive control. Nat Rev Neurosci 1:59-65. Medline

Newman LA, McGaughy J (2008) Cholinergic deafferentation of prefrontal cortex increases sensitivity to cross-modal distractors during a sustained attention task. J Neurosci 28:2642-2650. CrossRef Medline

Olsen SR, Bortone DS, Adesnik H, Scanziani M (2012) Gain control by layer six in cortical circuits of vision. Nature 483:47-52. CrossRef Medline

Parikh V, Kozak R, Martinez V, Sarter M (2007) Prefrontal acetylcholine release controls cue detection on multiple timescales. Neuron 56:141154. CrossRef Medline

Parikh V, Man K, Decker MW, Sarter M (2008) Glutamatergic contributions to nicotinic acetylcholine receptor agonist-evoked cholinergic transients in the prefrontal cortex. J Neurosci 28:3769-3780. CrossRef Medline

Parikh V, Ji J, Decker MW, Sarter M (2010) Prefrontal beta2 subunitcontaining and alpha7 nicotinic acetylcholine receptors differentially control glutamatergic and cholinergic signaling. J Neurosci 30:3518-3530. CrossRef Medline

Picciotto MR, Addy NA, Mineur YS, Brunzell DH (2008) It is not "either/ or": activation and desensitization of nicotinic acetylcholine receptors both contribute to behaviors related to nicotine addiction and mood. Progr Neurobiol 84:329-342. CrossRef Medline

Poorthuis RB, Goriounova NA, Couey JJ, Mansvelder HD (2009) Nicotinic actions on neuronal networks for cognition: general principles and longterm consequences. Biochem Pharmacol 78:668-676. CrossRef Medline

Poorthuis RB, Bloem B, Schak B, Wester J, de Kock CP, Mansvelder HD (2013) Layer-specific modulation of the prefrontal cortex by nicotinic acetylcholine receptors. Cereb Cortex 23:148-161. CrossRef Medline

Porter JT, Cauli B, Tsuzuki K, Lambolez B, Rossier J, Audinat E (1999) Selective excitation of subtypes of neocortical interneurons by nicotinic receptors. J Neurosci 19:5228-5235. Medline

Sarter M, Parikh V, Howe WM (2009) Phasic acetylcholine release and the volume transmission hypothesis: time to move on. Nat Rev Neurosci 10:383-390. CrossRef Medline

St John PA, Gordon H (2001) Agonists cause endocytosis of nicotinic acetylcholine receptors on cultured myotubes. J Neurobiol 49:212-223. CrossRef Medline

Trevelyan AJ, Sussillo D, Watson BO, Yuste R (2006) Modular propagation of epileptiform activity: evidence for an inhibitory veto in neocortex. J Neurosci 26:12447-12455. CrossRef Medline

Turchi J, Sarter M (1997) Cortical acetylcholine and processing capacity: effects of cortical cholinergic deafferentation on crossmodal divided attention in rats. Cogn Brain Res 6:147-158. CrossRef Medline

Wada E, McKinnon D, Heinemann S, Patrick J, Swanson LW (1990) The distribution of mRNA encoded by a new member of the neuronal nicotinic acetylcholine receptor gene family (alpha 5) in the rat central nervous system. Brain Res 526:45-53. CrossRef Medline

Winzer-Serhan UH, Leslie FM (2005) Expression of alpha5 nicotinic acetylcholine receptor subunit mRNA during hippocampal and cortical development. J Comp Neurol 481:19-30. CrossRef Medline

Wooltorton JR, Pidoplichko VI, Broide RS, Dani JA (2003) Differential desensitization and distribution of nicotinic acetylcholine receptor subtypes in midbrain dopamine areas. J Neurosci 23:3176-3185. Medline

World Health Organization (2012) www.who.int. 